\title{
Evaluation the Ability of "STONE Nephrolithometry Score in Predicting Stone Clearance Rate and Complications Rate by Modified Clavien Classification"
}

\author{
Khan Nazrul Islam ${ }^{1 *}$, S. A. Anwarul Quadir ${ }^{1}$, Md. Naushad Alam ${ }^{1}$, Md. Shawkat Alam², Bivash Boran ${ }^{3}$
}

\author{
${ }^{1}$ Assistant Professor, Department of Urology, National Institute of Kidney Diseases \& Urology (NIKDU), Dhaka, Bangladesh \\ ${ }^{2}$ Professor, Department of Urology, National Institute of Kidney Diseases \& Urology (NIKDU), Dhaka, Bangladesh \\ ${ }^{3}$ Assistant Professor, Department of Urology, Dhaka Medical College Hospital, Dhaka, Bangladesh
}

*Corresponding author: Khan Nazrul Islam

Abstract

Background: Percutaneous nephrolithotomy (PCNL) is the minimally invasive treatment modality for complex kidney calculi and considered as the standard treatment for large and complex renal stones. With the marked increase in the incidence and prevalence of renal stones, the use of percutaneous nephrolithotomy (PCNL) is now considered as the standard treatment for large and complex renal stones. New predictive tools have recently emerged to systematically and quantitatively assess kidney stone complexity to predict outcomes following PCNL. Objective: To prospectively evaluate the ability of 'stone nephrolithometry score in predicting stone clearance rate and complications rate by modified clavien classification (within 30 days of the procedure). Materials and Methods: A Prospective observational study done in the duration from Jun 2018 to July 2020. All patients having renal stone admitted for PCNL in Urology Department, National Institute of Kidney Diseases \& Urology (NIKDU), Dhaka, Bangladesh. Results: A total 100 patients fulfilled the inclusion and exclusion criteria for undergoing the PCNL for this study. Ninety patients had total clearance. In complete clearance group average stone size is $810 \mathrm{~mm}^{2}$, Avg tract length was $87.61 \mathrm{~mm}$ and average calyces involved was 1.1 with density of stone of 1024.9 HU. Conclusion: The STONE score is a simple and easy to apply system for predicting the complexity of the stone for PCNL, and stone clearance rate.

Keywords: STONE NEPHROMETRY SCORE, PCNL, Modified Clavien, Dindo.

Copyright $\odot 2021$ The Author(s): This is an open-access article distributed under the terms of the Creative Commons Attribution 4.0 International License (CC BY-NC 4.0) which permits unrestricted use, distribution, and reproduction in any medium for non-commercial use provided the original author and source are credited.

\section{INTRODUCTION}

Despite the availability of guidelines for managing urolithiasis there is no widely accepted standardised system for classifying stones in the upper urinary tract. With the marked increase in the incidence and prevalence of renal stones, the use of percutaneous nephrolithotomy (PCNL) is now considered as the standard treatment for large and complex renal stones. Percutaneous nephrolithotomy (PCNL) is the minimally invasive treatment modality for complex kidney calculi [1]. With the marked increase in the incidence and prevalence of renal stones, the use of percutaneous nephrolithotomy (PCNL) is now considered as the standard treatment for large and complex renal stones $[2,3]$. The stone score is calculated using five variables, abbreviated as an acronym 'STONE'. These include stone size, tract length (skin-to-stone distance), degree of obstruction, number of calyces involved and stone essence (density). New predictive tools have recently emerged to systematically and quantitatively assess kidney stone complexity to predict outcomes following PCNL: the Guy"s Stone Score, the CROES nomogram, S.T.O.N.E. nephrolithometry, and S-ReSC score. An ideal scoring system should include variables that both influence surgical planning and were predictive of postoperative outcomes. This review discusses the strengths, weaknesses, and commonalities of each of the above scoring systems. Recently, Okhunov et al., [4], proposed a novel quantitative scoring system which integrates five components measured from non-contrast-enhanced CT (NCECT) images before surgery to provide a picture of the complexity that can affect the percutaneous management of renal calculi. The stone score is calculated using five variables, abbreviated as an acronym "STONE". These include stone size, tract length (skin-to-stone distance), degree of obstruction, number of calyces involved and stone essence (density). Each feature from the NCCT KUB was graded on a 1-3 point scale. The scoring system can be used as a 
standard method for predicting the stone-free rate (SFR) after PCNL, and help in preoperative patient counselling, surgical planning and uniform academic reporting of the outcome. By this scoring system to assess peri-operative complications which were measured by modified clavien classification of surgical complications. In this study we tried to evaluate its efficacy of STONE nephrolithometry score in grading stone free rate and perioperative complications by modified clavien system. New predictive tools have recently emerged to systematically and quantitatively assess kidney stone complexity to predict outcomes following PCNL: the Guy ${ }^{\text {ee }}$ Stone Score, the CROES nomogram, S.T.O.N.E. nephrolithometry, and S-ReSC score. An ideal scoring system should include variables that both influence surgical planning and were predictive of postoperative outcomes. This review discusses the strengths, weaknesses, and commonalities of each of the above scoring systems.

\section{Materials and Methods}

A Prospective observational study done in the duration from Jun 2018 to July 2020. All patients having renal stone admitted for PCNL in Urology Department, National Institute of Kidney Diseases \& Urology (NIKDU), Dhaka, Bangladesh. Renal stone $\geq 2$ $\mathrm{cm}$ in largest diameter were included in the study, in some situation stone $\geq 1.5$ (in largest diameter) in lower pole stone or any stone that was not favourable for RIRS or ESWL were also included. Radiolucent stone, bilateral renal stone, presence of a ureteric stent, presence of nephrostomy tube, Active UTI, Skeletal deformity or special/abnormal anatomy of upper tract (i.e., horshoe kidney, PUJ obstruction, bifid system, etc.) were excluded from the study. In preoperative period nephrolithometric score was measured from the variables from NCCT of KUB region. The CT variables stone size, tract length, degree and presence ofobstruction (hydronephrosis), number of involved calyces and stone essence (density) was measured. Each of the variables was scored according to the predefined system and the STONE nephrolithometry score calculated using the sum of individual variable scores.

All procedures were performed with the patient prone, using single-tract dilatation with Alken dilators under fluoroscopic guidance. The procedure was continued until no stone could be identified by both nephroscopic and fluoroscopic inspection. Antegrade double , $\mathrm{Je}^{\mathrm{e}}$ was placed in majority of patients. Nephrostomy tube was inserted at the end of procedure in case of perforation of pelvicalyceal system, suspected residual fragments, incomplete clearance or bleeding from the tract. Str. Plain X-ray KUB were routinely performed on $3^{\text {rd }}$ post-op day. S.T.O.N.E. nephrolithometry was developed via a literature review of English language studies from 1976 to 2016 on Medline to identify the most clinically relevant and reproducible variables that had been shown to impact outcomes following PCNL. Its components were stone size, PCNL tract length, presence of obstruction, number of involved calyces, and stone density, measured from preoperative CT.A cohort of 117 PCNL patients was used to evaluate the predictive value of the S.T.O.N.E. nephrolithometry. A "low" score of 3 to 5 demonstrated a correlation with SF rates of $94 \%$ to $100 \%$, a "moderate" score of 6 to 8 correlated with a SF rate of $83 \%$ to $92 \%$, and "high" scores of 9 to 13 correlated with SF rates ranging from $27 \%$ to $64 \%$.

S.T.O.N.E. Nephro-Scoring based on five Variables from preoperative noncontrast comlithometry puted tomography stone size:

\begin{tabular}{|l|l|}
\hline $\mathrm{S}=$ Stone size & $1: 0-399 \mathrm{~mm}^{2}$ \\
& $2: 400-799 \mathrm{~mm}^{2}$ \\
& $3: 800-1599 \mathrm{~mm}^{2}$ \\
& $4:>1600 \mathrm{~mm}^{2}$ \\
\hline T=Tract length & $1:<100 \mathrm{~mm}$ \\
& $2:>100 \mathrm{~mm}$ \\
\hline O=Obstruction & $1:$ No or mild dilatation \\
& $2:$ Moderate to severe dilatation \\
\hline N=Number of involved calyces & $1: 1$ Calyx involved \\
& $2: 2: 3$ Calyces involved \\
\hline E= Essence (Stone density) & $1:<950 \mathrm{HU}$ \\
& $2:>950 \mathrm{HU}$ \\
\hline
\end{tabular}

\section{RESULTS}

A total 100 patient's fulfiled the inclusion and exclusion criteria for undergoing the PCNL for this study. Fifty five patients were male with average age 41 years and 45 patients were female with average age was 41 years. Out of 100 patients 90 patients had complete clearance and 10 patients had incomplete clearance. In complete clearance group average stone size was 810 $\mathrm{mm}^{2}$ and incomplete group average stone size was 967 $\mathrm{mm}^{2}$ and which statistially significant that was if stone size was increased stone clearance rate decreases. In complete clearance group average stone size was 810 $\mathrm{mm}^{2}$ and incomplete group average stone size was 967 $\mathrm{mm}^{2}$ and which statistially significant that was if stone size was increased stone clearance rate decreases. Degree of hydronephros was not related to stone clearance rate. 
Khan Nazrul Islam et al; Sch J App Med Sci, Feb, 2021; 9(2): 277-282

Table-1: The Patients between complete and incomplete Clearance of different stone score. Skin to Stone Distance, Degree of Hydronephrosis, No. Of Calyces, Essence of Stone and „STONE ${ }^{c e}$ SCORE

\begin{tabular}{|l|l|l|l|l|}
\hline & Complete Clearance & Incomplete Clearance & Total & P Value \\
\hline STONE SIZE $\left(\mathrm{mm}^{2}\right)$ & 810.58 & 967.6 & 826.28 & $<0.05$ \\
\hline Skin To Stone Distance & $87.61 \mathrm{~mm}$ & $90.2 \mathrm{~mm}$ & 87.87 & $>0.05$ \\
\hline Degree Of Hydronephrosis & 1.4 & 1.6 & 1.5 & $>0.05$ \\
\hline No. Of Calyces & 1.1 & 1.7 & 1.16 & 0.02 \\
\hline Essence Of Stone & 1024.9 & 1089.7 & 1031.4 & $>0.05$ \\
\hline "STONE" SCORE & 7.21 & 8.6 & 7.35 & 0.002 \\
\hline
\end{tabular}

In complete clearance group average number of calyx involved were 1.1 and incomplete group average number of calyx was involved was 1.7 and which was statistially significant that was if stone was found in multiple calyces then success rate decreases. In complete clearance group average stone density was 1024.9 HU and incomplete group average stone density was $1089.7 \mathrm{HU}$ and which was statistially not significant that was if stone density was increased stone clearance does not change. In this chart $\mathrm{P}$ value was statistically significant so NEPHROMETRIC RENAL SCORE was significantly correlated with operative success rate.

Table-2: Intraoperative time was documented and compared between the patients group of different stone score

\begin{tabular}{|l|l|l|l|}
\hline Stone Score & Group A & Group B & P value \\
\hline Operative time (min) & 56 & 72 & 0.011 \\
\hline Modified Clavien Score & 0.82 & 1.8 & 0.021 \\
\hline
\end{tabular}

Group A - NEPHROMETRIC SCORE 6, 7, 8

Group B - NEPHROMETRIC SCORE 9, 10, 11

Likewise Clavein Dindo score was noted and compared.

Group A - NEPHROMETRIC SCORE 6, 7, 8

Group B - NEPHROMETRIC SCORE 9, 10, 11

It obvious from the table that clavien score significantly correlated with NEPHROMETRIC RENAL SCORE.

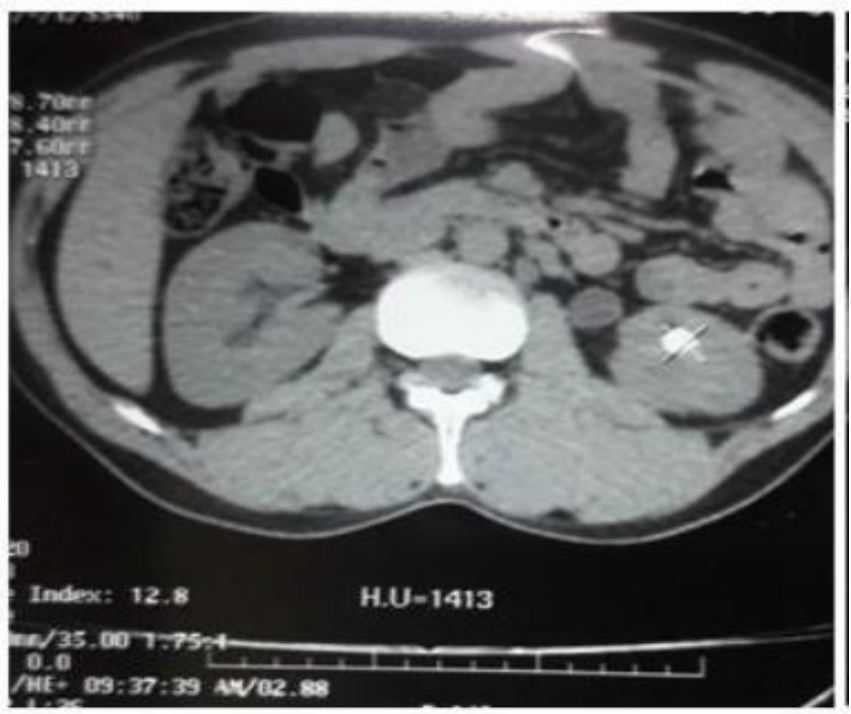

Fig-1: Showing stone size 


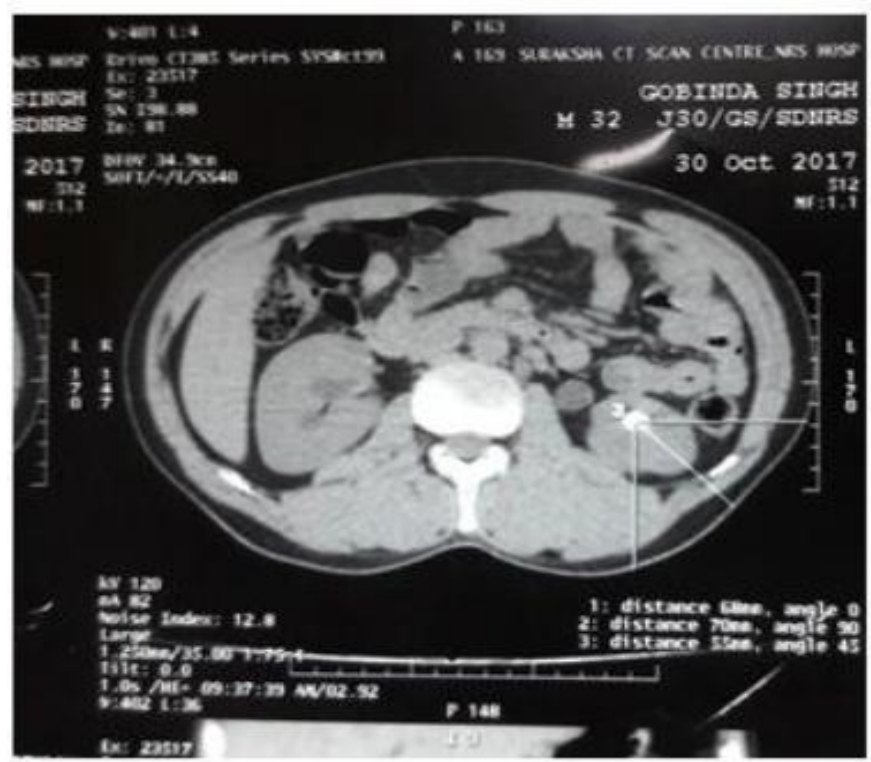

Fig-2: Showing skin to stone distance

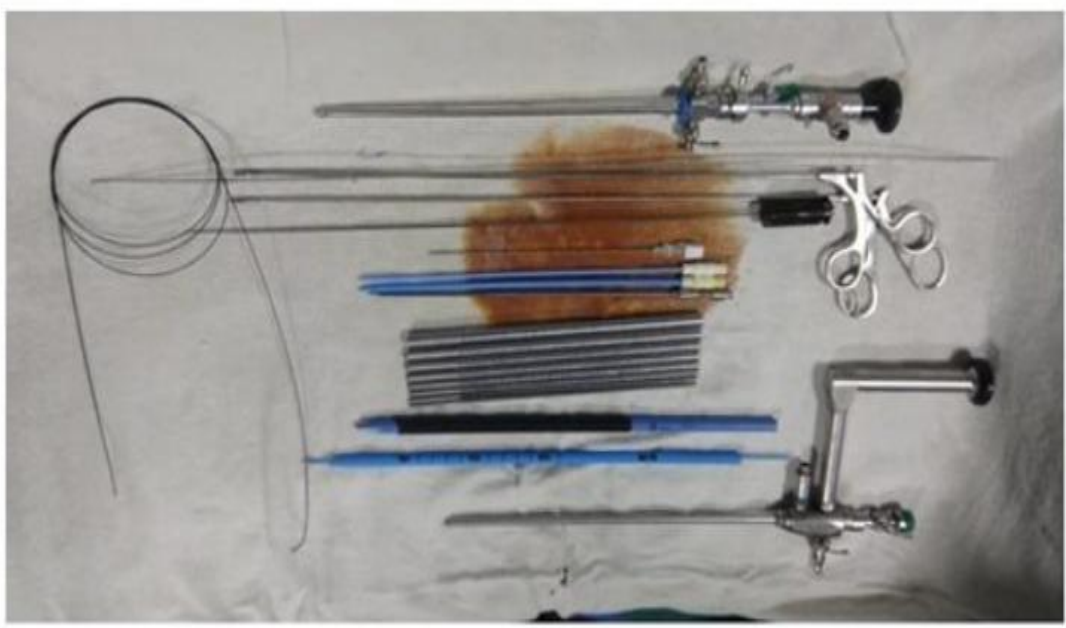

Fig-3: Instrument trolley for pcnl

\section{DISCUSSION}

In the general population the incidence of urolithiasis was $5-10 \%$ and nearly $30 \%$ of the workload in an active urology department was related to treating urinary stones $[5,6]$. For large and complex kidney stones PCNL was an important surgical intervention, and its success depends on several variables. Some of these can be predicted before surgery, i.e., stone burden and upper tract anatomy, but success also depends on surgical experience [7]. To establish an accurate diagnosis and to determine the optimum treatment and surgical planning, preoperative imaging was a critical step [8]. CT has become the leading imaging method for urolithiasis, providing high-resolution spatial imaging along with multiplanar reconstruction for the accurate determination of stone complexity i.e. size and distribution, pelvicalyceal anatomy and anatomical relationship with other structures, hence contributing to surgical planning $[9,10]$. Several scoring systems have been developed for predicting the SFR after shock-wave lithotripsy, retrograde intrarenal surgery and PCNL [11,
12]. These have incorporated different variables that can influence success rates, but the imaging methods on which these systems were developed show some inconsistencies [13]. The scoring systems in contemporary use for predicting the outcome of PCNL were Guys stone score, the STONE nephrolithometry score, the Clinical Research Office of Endo Urological Society (CROES) nephrolithometric nomogram, and staghorn morphometry. These have attempted to incorporate important variables in an efficient and simple manner to quantify renal stone complexity [13]. An optimal scoring system should be quick, simple, reproducible and easily implemented and must have a good correlation with SFRs and complications [14]. Several scoring systems have been developed for predicting the SFR after shock-wave lithotripsy, retrograde intrarenal surgery and PCNL [11, 12]. These have incorporated different variables that can influence success rates, but the imaging methods on which these systems were developed show some inconsistencies. Okhunov et al., [4], developed and validated the STONE score from preoperative NCECT, based on a 
Khan Nazrul Islam et al; Sch J App Med Sci, Feb, 2021; 9(2): 277-282

Medline review of English-language studies from 1976 to 2016 and identifying clinically relevant variables affecting the outcomes of PCNL. This scoring system was externally validated in a multi-institutional study with 850 patients, and showed that the model was significantly associated with the SFR, overall complication rate, estimated blood loss, operative duration and length of hospital stay. In contrast to the other scoring systems, the STONE score uses variables that were easy to calculate, derived from NCECT (most common diagnostic method used for evaluating patients with stone) and requires no specialized software. All patients with radiolucent stone, bilateral renal stone, presence of a ureteric stent and presence of nephrostomy tube, active UTI, skeletal deformity or special/abnormal anatomy of upper tract (i.e. horshoe kidney, PUJ obstruction, bifid system, etc), pregnancy, patients who were unfit for surgery, untreated coagulopathy were excluded from study. In our study total number of patients were 100 and overall complete clearance rate $90 \%$. Residual stone (stone> $4 \mathrm{~mm}$ in size on KUB radiography at one month postoperative film) found in $10 \%$ patients. Fifty five patients were male with average age 41 years and 45 patients were female with average age was 41 years with similar success rate. In complete clearance group average stone size was $810 \mathrm{~mm}^{2}$ and incomplete group average stone size was $926 \mathrm{~mm}^{2}$ and which was statistially significant that was if stone size increased stone clearance decreases. As $\mathrm{P}$ value was less than 0.05 so Skin to stone distance does not change the operative success rate. As shown in the table in complete clearance group average stone density was 1024.9 HU and incomplete group average stone density was $1089.7 \mathrm{HU}$ and which was statistially not significant that was if stone density increased stone clearance does not change. Degree of hydronephrosis not related to stone clearance rate according to my data. As shown in this graph in complete clearance group average number of calyx was involved 1.1 and in incomplete group average number of calyx was involved 1.7 and which was statistially significant that was if stone was found in multiple calyces then success rate decreases. According to the graphs number of access was correlated with NEPHROMETRIC SCORE as P value was less than 0.5 . So stone was found in multiple calyces and NEPHROMETRIC SCORE were correlated with multiple puncture. Operative time was significantly increases with incomplete clearance group and when nephrometric score increases. It also helps to define the complexity of the stone, and benefit not only patient counselling, but also auditing, training and revalidation, and comparison between different centres, surgeons and techniques by uniform and standardised reporting [1518]. It obvious from the table and graph that clavien score significantly correlated with NEPHROMETRIC RENAL SCORE. In the present study, tract length, stone density and the degree of obstruction were not associated with a lower SFR. Others have reported that patients with a greater stone density and consequently longer tract (skinto-stone distance) were technically challenging, and this could affect the perioperative variables. We did not determine the accuracy of the score, nor did we assess the inter-observer reliability, but we found this scoring system to correlate with the SFR, with lower scores predicting the likely probability of stone clearance. Although the difference between mean STONE score of the stone-free and residual-stone group was significant, it was small ( $<1$ point). Similarly, a higher STONE score, with a more complex procedure, was correlated with a longer operation; it was not reflected in a greater likelihood of complications. The stone score was calculated using five variables, abbreviated as an acronym ,STONE ${ }^{\mathrm{ec}}$. These include stone size, tract length (skin-to-stone distance), degree of obstruction, number of calyces involved and stone essence (density) were measured. Each of the variables were scored according to the predefined system and the STONE nephrolithometry score calculated using the sum of individual variable scores. All procedures were performed with the patient prone, using single-tract dilatation with Alken dilators under fluoroscopic guidance. Stones were fragmented using either the pneumatic Lithoclast, or simultaneous combined therapy with the Lithoclast and Holmium YAG laser lithotripter. The procedure has to be continued until no stone could be identified by both nephroscopic and fluoroscopic inspection. For heavy stone burden and multiple calyceal stone involvement multiple session may be required. Antegrade double „J $\mathrm{J}^{\mathrm{ee}}$ has to be placed in majority of patients. Nephrostomy tube were inserted at the end of procedure in case of perforation of pelvicalyceal system, suspected residual fragments, incomplete clearance or bleeding from the tract. Plain X-ray KUB were routinely performed on $3^{\text {rd }}$ post-op day.

\section{Conclusion}

The STONE score was a simple and easy to apply system for predicting the complexity of the stone for PCNL, and stone clearance. Prospective studies with a larger sample were required to further confirm these findings.

\section{REFERENCES}

1. Muhammad Farhan, A., Syed, M., Nazim, A., Basit Salam, B., \& Hammad, M. (2015). Ather aa Section of Urology, Department of Surgery, Aga Khan University, Karachi, Pakistanb Department of Radiology, Aga Khan University, Karachi, Pakistan. Received 4 June 2015, Received in revised form 2 July 2015, Accepted 22 July 2015 Available online 29 August 2015.

2. Turk, C., Knoll, T., \& Petrik, A. (2015). European Association of Urology. EUA Guidelines on Urolithiasis. Available at <http:// uroweb.org/guideline/urolithiasis/> [accessed June 2015]. 
Khan Nazrul Islam et al; Sch J App Med Sci, Feb, 2021; 9(2): 277-282

3. Rosette, J. D. L., Assimos, D., Desai, M., Gutierrez, J., Lingeman, J., Scarpa, R., \& Tefekli, A. (2011). The clinical research office of the endourological society percutaneous nephrolithotomy global study: indications, complications, and outcomes in 5803 patients. Journal of endourology, 25(1), 11-17.

4. Okhunov, Z., Friedlander, J. I., George, A. K., Duty, B. D., Moreira, D. M., Srinivasan, A. K., ... \& Okeke, Z. (2013). STONE nephrolithometry: novel surgical classification system for kidney calculi. Urology, 81(6), 1154-1160.

5. Authors Okhunov, Zhamshid (New Hyde Park, NY); Lesser, Martin; Friedlander, Justin; Duty, Brian; George, Arvin; Shrinivasan, Arun; Smith, Arthur; Okeke, Zeph. Nephrolithometry: A Novel Surgicalclassification System For Renal Stones.

6. Jeong, C. W., Jeong, S. J., Hong, S. K., Lee, S. B., $\mathrm{Ku}$, J. H., Byun, S. S., ... \& Lee, S. E. (2012). Nomograms to predict the pathological stage of clinically localized prostate cancer in Korean men: comparison with western predictive tools using decision curve analysis. International Journal of Urology, 19(9), 846-852.

7. Smith, A., Averch, T. D., Shahrour, K., Opondo, D., Daels, F. P., Labate, G., ... \& Croes Pcnl Study Group. (2013). A nephrolithometric nomogram to predict treatment success of percutaneous nephrolithotomy. The Journal of urology, 190(1), 149-156.

8. Magrill, D., Patel, U., \& Anson, K. (2013). Impact of imaging in urolithiasis treatment planning. Current opinion in urology, 23(2), 158163.

9. Fulgham, P. F., Assimos, D. G., Pearle, M. S., \& Preminger, G. M. (2013). Clinical effectiveness protocols for imaging in the management of ureteral calculous disease: AUA technology assessment. The Journal of urology, 189(4), 12031213.

10. Lipkin, M. E., \& Preminger, G. M. (2013). Imaging techniques for stone disease and methods for reducing radiation exposure. Urologic Clinics, 40(1), 47-57.

11. Wiesenthal, J. D., Ghiculete, D., Ray, A. A., Honey, R. J. D. A., \& Pace, K. T. (2011). A clinical nomogram to predict the successful shock wave lithotripsy of renal and ureteral calculi. The Journal of urology, 186(2), 556-562.

12. Resorlu, B., Unsal, A., Gulec, H., \& Oztuna, D. (2012). A new scoring system for predicting stonefree rate after retrograde intrarenal surgery: the "resorlu-unsal stone score". Urology, 80(3), 512518.

13. Labadie, K., Okhunov, Z., Akhavein, A., Moreira, D. M., Moreno-Palacios, J., Del Junco, M., ... \& Landman, J. (2015). Evaluation and comparison of urolithiasis scoring systems used in percutaneous kidney stone surgery. The Journal of urology, 193(1), 154-159.

14. Thomas, K., Smith, N. C., Hegarty, N., \& Glass, J. M. (2011). The Guy's stone score-grading the complexity of percutaneous nephrolithotomy procedures. Urology, 78(2), 277-281.

15. De Sio, M., Autorino, R., Quarto, G., Calabro, F., Damiano, R., Giugliano, F., ... \& D'Armiento, M. (2008). Modified supine versus prone position in percutaneous nephrolithotomy for renal stones treatable with a single percutaneous access: a prospective randomized trial. european urology, 54(1), 196-203.

16. de la Rosette, J. J., Laguna, M. P., Rassweiler, J. J., \& Conort, P. (2008). Training in percutaneous nephrolithotomy - a critical review. European urology, 54(5), 994-1003.

17. Allen, D., O'Brien, T., Tiptaft, R., \& Glass, J. (2005). Defining the learning curve for percutaneous nephrolithotomy. Journal of endourology, 19(3), 279-282.

18. Papatsoris, A. G., Shaikh, T., Patel, D., Bourdoumis, A., Bach, C., Buchholz, N., ... \& Junaid, I. (2012). Use of a virtual reality simulator to improve percutaneous renal access skills: a prospective study in urology trainees. Urologia internationalis, 89(2), 185-190. 